\title{
The efficacy and safety of tranexamic acid for reducing blood loss following simultaneous bilateral total knee arthroplasty: a multicenter retrospective study
}

Guorui Cao ${ }^{1 \dagger}$, Guo Chen ${ }^{2 \dagger}$, Qiang Huang ${ }^{1}$, Zeyu Huang ${ }^{1}$, Peter G. Alexander ${ }^{3}$, Hang Lin ${ }^{3}$, Hong Xu', Zongke Zhou ${ }^{1}$ and Fuxing Pei ${ }^{*}$ (D)

\begin{abstract}
Background: The purpose of the study was to evaluate whether tranexamic acid (TXA) administration could reduce blood loss and transfusion risk after simultaneous bilateral total knee arthroplasty (SBTKA).

Methods: As a multicenter retrospective study, a total of 575 patients were assigned into three groups on the basis of TXA usage, including intravenous (IV) group (1 g IV TXA 5-10 min prior to the incision), combined group (1 g IV TXA combined with intra-articular injection of $1 \mathrm{~g}$ TXA prior to the closure every knee) and control group (no TXA use). The primary outcomes were total blood loss (TBL). The secondary outcomes were maximum hemoglobin ( $\mathrm{Hb})$ and hematocrit (Hct) drop, transfusion rate, drain volume, length of stay, hospitalization expenses and the incidence of complications.

Results: The mean TBL in control group $(1685.0 \pm 571.4 \mathrm{~mL})$ were higher than that in IV group $(1061.1 \pm 689.6 \mathrm{~mL}$, $p=0.006$ and combined group $(988.3 \pm 559.3 \mathrm{~mL}, p=0.003)$. The maximum $\mathrm{Hb}$ and Hct drop in combined group $(28.5 \pm 13.4 \mathrm{~g} / \mathrm{L}, p=0.016 ; 0.074 \pm 0.053, p<0.001)$ and IV group $(28.8 \pm 14.5 \mathrm{~g} / \mathrm{L}, p=0.025 ; 0.082 \pm 0.056, p=0.001)$ were lower than those in control group (33.4 $\pm 14.0 ; 0.131 \pm 0.049)$. But the difference between IV and combined groups was not significant. The similar trend was detected on drain volume, length of stay and hospitalization expenses. The incidence of complications did not differ significantly among the three groups $(p>0.05)$.
\end{abstract}

Conclusions: The study indicates that TXA could reduce blood loss with no apparent increase in the incidence of complications during SBTKA.

Keywords: Total knee arthroplasty, Simultaneous bilateral, Tranexamic acid, Blood loss, Transfusion

\footnotetext{
*Correspondence: peifuxingwestchina@yeah.com;

peifuxingwestchina@163.com

${ }^{\dagger}$ Guorui Cao and Guo Chen contributed equally to this work, as co-first author.

${ }^{1}$ Department of Orthopaedic surgery, West China Medical School, West

China Hospital, Sichuan University, 37\# Guoxue Road, Chengdu, Sichuan

Province 610041, People's Republic of China

Full list of author information is available at the end of the article
}

(c) The Author(s). 2019 Open Access This article is distributed under the terms of the Creative Commons Attribution 4.0 International License (http://creativecommons.org/licenses/by/4.0/), which permits unrestricted use, distribution, and reproduction in any medium, provided you give appropriate credit to the original author(s) and the source, provide a link to the Creative Commons license, and indicate if changes were made. The Creative Commons Public Domain Dedication waiver (http://creativecommons.org/publicdomain/zero/1.0/) applies to the data made available in this article, unless otherwise stated. 


\section{Background}

Total knee arthroplasty (TKA) is always accompanied by massive blood loss, which increase the risk of anemia and allogeneic blood transfusion, leading to higher incidence of wound complications, immunologic reactions, transmission of disease and delaying functional recovery [1-3]. Therefore, blood management associated with TKA is an important and widely-discussed topic for surgeons. Blood management for simultaneous bilateral total knee arthroplasty (SBTKA) patients is more challenging than in primary TKA.

The TKA could motivate the process of fibrinolysis, which is the main reason of perioperative blood loss [4]. It was reported that Tranexamic acid (TXA) was effective and safe in inhibiting hyperfibrinolysis and reducing blood loss in SBTKA [5-7]. TXA could be applied intravenously, topically or combination of multiple routes. Previous studies have showed that intravenous (IV) or local administration of TXA are effective and safe in reducing blood loss and transfusion need in SBTKA [5, 6, 8]. However, studies to evaluate the efficacy of combined IV and intra-articular administration of TXA are rare. Moreover, the study sample of previous studies was too small to provide powerful evidence for efficacy and safety of TXA following SBTKA. Thus, the purpose of the study was to evaluate whether TXA administration could reduce blood loss and transfusion risk after SBTKA through a multicenter, large sample, retrospective study.

\section{Methods}

\section{Patients and design}

A multicenter database was established to evaluate the efficacy and safety of perioperative management for total hip and knee arthroplasty in China in January 2013, sponsored by the Chinese Health Ministry (201302007). This study was a multicenter retrospective study and the data were from 4 teaching hospitals in the database [9]. The study was approved by our institutional review board (2012-268).

We identified all cases of SBTKA using International Classification of Diseases, Tenth Revision, Clinical Modification (ICD-10-CM) procedure codes from January 2015 to June 2018. SBTKA was defined as procedure performed under a single episode of anesthesia. The patients with a primary diagnosis code of infection, fracture, or malignancy, with incomplete demographic information, primary and bilateral single-stage procedures were excluded. In addition, we excluded those presence of a congenital or acquired clotting disorder, a history of deep venous thrombosis (DVT) or pulmonary embolism (PE), cardiovascular problems, or a known allergy to TXA. What was more, the patients were excluded when the intraoperative blood loss was more than $400 \mathrm{~mL}$ during the first knee surgery. Totally, 575 patients undergoing SBTKA were recruited. The patients were divided into intravenous (IV) group $(1 \mathrm{~g} / 100 \mathrm{~mL} \mathrm{IV}$ TXA 5-10 min before the skin incision), combined (IV + topical use) group (Intra-articular injection of $1 \mathrm{~g} / 100$ $\mathrm{mL}$ before the closure every knee, totally $2 \mathrm{~g}$ per patient) and control group (no TXA use).

\section{Surgery procedure and perioperative management}

All the TKAs were performed using the midline skin incision and medial parapatellar approach. A measured resection technique was used in the surgery. The tourniquet was utilized in all patients which was inflated prior to skin incision and deflated immediately prior to closure. All patients received drains, which were removed when the volume of drain was less than $30 \mathrm{~mL} / \mathrm{h}$. The procedures were conducted under general or lumbar anesthesia. Patients received half-dose of lowmolecular-weight heparin (LMWH; $2000 \mathrm{IU}$ in $0.2 \mathrm{ml}$; Clexane, Sanofi-Aventis, France) or $10 \mathrm{mg}$ Rivaroxaban (Xarelto, Bayer, Germany) 6-8 h postoperatively, repeating once a day for 14 days. Doppler ultrasound examinations were used routinely to detect DVT. Transfusions were applied if the hemoglobin $(\mathrm{Hb})$ level was $<70 \mathrm{~g} / \mathrm{L}$ or $70-100 \mathrm{~g} / \mathrm{L}$ with symptoms of anemia, such as bad mental status, palpitation or shortness of breath not due to other causes.

\section{Outcome measurements}

The primary outcomes were total blood loss (TBL), calculated on the basis of the Gross and Nadler formula [10, 11]. $\mathrm{TBL}=$ patient's blood volume $(\mathrm{PBV}) \times\left(\mathrm{Hct}_{\text {pre }}-\mathrm{Hct}_{\text {post }}\right) /$ Hct $_{\text {ave }}\left(\right.$ Hct $_{\text {pre }}=$ the initial preoperative Hct level, Hct $_{\text {post }}=$ the Hct on the morning of POD3. PBV $=\mathrm{k}_{1} \times$ height $(\mathrm{m})^{3}+\mathrm{k}_{2} \times$ weight $(\mathrm{kg})+\mathrm{k}_{3}\left(\mathrm{k}_{1}=0.3669, \mathrm{k}_{2}=0.03219\right.$, and $\mathrm{k}_{3}=0.6041$ for men; and $\mathrm{k}_{1}=0.3561, \mathrm{k}_{2}=0.03308$, and $\mathrm{k}_{3}=0.1833$ for women, Hct $_{\mathrm{ave}}=$ the average of the Hct pre and $\left.\mathrm{Hct}_{\text {post }}\right)$. If either reinfusion or allogeneic transfusion was performed, the TBL was equal to the loss calculated from the change in Hct plus the volume transfuse [12]. The secondary outcomes were maximum $\mathrm{Hb}$ and hematocrit (Hct) drop, transfusion rate, drain volume, length of stay (LOS), hospitalization expenses and the incidence of complications. The blood sample was collected and analyzed preoperatively, postoperative day (POD) 1 and 3. The maximum $\mathrm{Hb}$ and Hct drop was defined as the difference between the preoperative $\mathrm{Hb}$, Hct and the lowest postoperative $\mathrm{Hb}$, Hct during hospitalization.

\section{Statistical analysis}

The SPSS version 22.0 (SPSS Inc. USA) was used to evaluate all statistical analyses. The continuous variables were compared using the one-way analysis of variance, Wilcoxon Mann-Whitney $U$ test or independent $t$-test. 
The categorical variables were compared using Pearson chi-square test or Fisher exact test. The $p$-value $<0.05$ was considered to be statistically significant.

\section{Results}

\section{Patients' demographics}

A total of 623 patients recruited for SBTKA were screened for eligibility from January 2015 to June 2018. However, 48 patients were excluded because of the exclusion criteria and remaining 575 patients (192 in IV group, 135 in combined group and 248 in control group) were observed and studied. The baseline characteristics of the patients among the three groups were comparable (Table 1).

\section{Blood loss}

The mean TBL in control group $(1685.0 \pm 571.4 \mathrm{~mL})$ were higher than that in IV group $(1061.1 \pm 689.6 \mathrm{~mL}$, $p=0.006)$ and combined group $(988.3 \pm 559.3 \mathrm{~mL}, p=$ $0.003)$. The transfusion rate in control group (23.0\%) were higher than that in IV group $(14.1 \%, p=0.018)$ and combined group $(11.1 \%, p=0.005)$. The difference of TBL and transfusion rate between IV and combined groups was not significant. The similar trend was detected on drain volume. The maximum $\mathrm{Hb}$ and $\mathrm{Hct}$ drop in combined group $(28.5 \pm 13.4 \mathrm{~g} / \mathrm{L}, \quad p=0.016$; $0.074 \pm 0.053, p<0.001)$ and IV group $(28.8 \pm 14.5 \mathrm{~g} / \mathrm{L}$, $p=0.025 ; 0.082 \pm 0.056, p=0.001)$ were lower than those in control group $(33.4 \pm 14.0 ; 0.131 \pm 0.049)$. These statistical difference existed in LOS and hospitalization expenses between IV group and control group, as well as combined group and control group. However, the differences between IV and combine groups did not reach statistical significance. The outcome of blood loss was summarized in Table 2.

\section{Complications}

There were 1 patient in IV group, 1 in combine group and 3 in control group developing DVT in the study. In addition, two patients in IV group and one patient in control group developed superficial infection. No PE, cardiac infarction, acute renal failure or deep infection were detected. The incidence of complications was similar among the three groups (Table 3). All patients were discharged uneventfully after symptomatic treatment.

\section{Discussion}

Perioperative blood loss in SBTKA has been a crucial issue because SBTKA is associated much blood loss and higher risk of bleeding complications [13, 14]. The efficacy and safety of TXA to reduce blood loss has been well studied recently. However, the usage was single and the combination of TXA was rare [5, 6, 8]. Moreover,

Table 1 Baseline characteristics

\begin{tabular}{|c|c|c|c|c|}
\hline Baseline Characteristic & IV group $(n=192)$ & Combined group $(n=135)$ & Control group $(n=248)$ & $P$ \\
\hline$\overline{\text { Age }(y)}$ & $66.2 \pm 7.9$ & $65.8 \pm 9.1$ & $66.6 \pm 9.5$ & 0.675 \\
\hline Gender(M/F) & $32 / 160$ & $23 / 112$ & $43 / 205$ & 0.983 \\
\hline BMI $\left(\mathrm{kg} / \mathrm{m}^{2}\right)$ & $27.1 \pm 3.8$ & $27.6 \pm 3.3$ & $27.0 \pm 3.5$ & 0.230 \\
\hline Diagnose (OA/IA) & $183 / 9$ & $126 / 9$ & $238 / 10$ & 0.514 \\
\hline Hypertension & 67 (34.9\%) & 59 (43.7\%) & 85 (34.3\%) & 0.154 \\
\hline Diabetes & $20(10.4 \%)$ & $17(12.6 \%)$ & $21(8.5 \%)$ & 0.433 \\
\hline Preoperative $\mathrm{Hb}(\mathrm{g} / \mathrm{L})$ & $140.8 \pm 12.2$ & $143.2 \pm 10.8$ & $141.4 \pm 10.4$ & 0.432 \\
\hline Preoperative Hct & $0.415 \pm 0.035$ & $0.420 \pm 0.032$ & $0.415 \pm 0.037$ & 0.758 \\
\hline PBV $(\mathrm{mL})$ & $4047.3 \pm 505.6$ & $4060.4 \pm 559.1$ & $4020.3 \pm 532.1$ & 0.749 \\
\hline Anticoagulation methods & & & & 0.398 \\
\hline LMWH & 109 & 86 & 153 & \\
\hline Rivaroxaban & 83 & 49 & 95 & \\
\hline Anesthesia method & & & & 0.578 \\
\hline General & 152 & 112 & 195 & \\
\hline Regional & 40 & 23 & 53 & \\
\hline ASA class & & & & 0.852 \\
\hline $1-2$ & 188 & 131 & 241 & \\
\hline$\geq 3$ & 4 & 4 & 7 & \\
\hline Operating time (min) & $120.3 \pm 37.1$ & $153.8 \pm 43.9$ & $139.3 \pm 39.1$ & $<0.001^{*}$ \\
\hline
\end{tabular}

$B M I$ Body mass index $=$ Weight $/$ Height $^{2}$, OA Osteoarthritis, IA Inflammatory arthritis, Hb Hemoglobin, Hct Hematocrit, $P B V$ patient blood volume, LMWH lowmolecular-weight heparin, ASA American Society of Anesthesiologists

*Significant difference 
Table 2 Comparison of Blood Loss, LOS and expenses

\begin{tabular}{|c|c|c|c|c|c|c|c|}
\hline Variable & $\begin{array}{l}\text { IV group } \\
(n=192)\end{array}$ & $\begin{array}{l}\text { Combined group } \\
(n=135)\end{array}$ & $\begin{array}{l}\text { Control group } \\
(n=248)\end{array}$ & $P$ & $P 1$ & $P 2$ & P3 \\
\hline $\mathrm{TBL}(\mathrm{mL})$ & $1061.1 \pm 689.6$ & $988.3 \pm 559.3$ & $1685.0 \pm 571.4$ & $0.006^{*}$ & 0.693 & $0.003^{*}$ & $0.003^{*}$ \\
\hline Transfusion rate & $27(14.1 \%)$ & $15(11.1 \%)$ & $57(23.0 \%)$ & $0.005^{*}$ & 0.818 & $0.018^{*}$ & $0.005^{*}$ \\
\hline Drain volume & $432.9 \pm 262.6$ & $393.2 \pm 250.3$ & $663.9 \pm 199.4$ & $<0.001^{*}$ & 0.348 & $0.005^{*}$ & $<0.001^{*}$ \\
\hline Maximum $\mathrm{Hb}$ drop & $28.8 \pm 14.5$ & $28.5 \pm 13.4$ & $33.4 \pm 14.0$ & $0.015^{*}$ & 0.710 & $0.025^{*}$ & $0.016^{*}$ \\
\hline Maximum Hct drop & $0.082 \pm 0.056$ & $0.074 \pm 0.053$ & $0.131 \pm 0.049$ & $0.001^{*}$ & 0.614 & $0.001^{*}$ & $<0.001^{*}$ \\
\hline LOS & $7.8 \pm 6.6$ & $7.7 \pm 4.8$ & $10.1 \pm 3.8$ & 0.781 & $<0.001^{*}$ & $<0.001^{*}$ & $<0.001^{*}$ \\
\hline Expenses $\Delta$ & $93,625.8 \pm 16,516.4$ & $94,255.1 \pm 10,453.5$ & $99,174.1 \pm 14,032.7$ & $0.005^{*}$ & 0.676 & $0.005^{*}$ & $0.006^{*}$ \\
\hline
\end{tabular}

TBL Total blood loss, $H b$ Hemoglobin, Hct Hematocrit, $P O D$ postoperative day. LOS: length of stay; $P$ represents $P$ value of IV vs combined vs control group, $\mathrm{P} 1$ represents $P$ value of IV vs combined group, P2 represents $P$ value of IV vs control group, P3 represents $P$ value of combined vs control group

$\Delta$ Results were presented as Chinese yuan

*Significant difference

the research was small. There was a paucity of multicenter, large sample studies on the efficacy and safety of TXA in the setting of SBTKA. In this research, we found that IV TXA or combining IV and intra-articular injection of TXA both could decrease blood loss, drain volume, $\mathrm{Hb}$ and Hct drop, as well as LOS and expenses following SBTKA.

The application of TXA has been shown to reduce blood loss and transfusion requirements in patients undergoing primary TKA. However, the studies related to SBTKA using TXA are sparse $[5,6,8,15,16]$. A randomized controlled trail conducted by Chen et al. showed that fixed dose of IV TXA $(1 \mathrm{~g} / 100 \mathrm{~mL})$ for patients undergoing SBTKA was effective and safe in reducing total blood loss and allogeneic blood transfusion needs without any additional thromboembolic risk [6]. Karam and colleague's study came to a similar conclusion [16]. Bagsby et al. conducted that IV TXA (10 mg/ $\mathrm{kg}$, preoperatively) was an effective tool in reducing the transfusion rates in SBTKA [5]. Karaaslan et al. evaluated the usage of combining IV $(15 \mathrm{mg} / \mathrm{kg}$ preoperatively and continuing $10 \mathrm{mg} / \mathrm{kg} / \mathrm{h}$ for $3 \mathrm{~h}$ postoperatively) and intra-articular TXA $(3 \mathrm{~g} / 100 \mathrm{~mL}$ saline after clamping of the drain) administration, showing that TXA could reduce blood loss with negligible side effects during SBTKA [15]. Another study performed by Suh et al. found that IV iron supplementation combined with intra-articular administration of TXA $(2 \mathrm{~g} / 20 \mathrm{ml}$ saline $)$ was an effective strategy for reducing $\mathrm{Hb}$ drop and transfusion risk following SBTKA [8]. Prieto et al. found that IV TXA $(20 \mathrm{mg} / \mathrm{kg})$ in SBTKA could effectively reduce blood loss, maintain postoperative $\mathrm{Hb}$ and $\mathrm{Hct}$ levels, and significantly decrease blood transfusion rates [7]. However, the number of cases was only 20-60 and persuasiveness was a little low. So we conducted this retrospective, large sample research, showing that TXA could reduce blood loss, transfusion rate, drain volume, maximum $\mathrm{Hb}$ and Hct drop, LOS and hospitalization expenses. But the difference of administration of single IV TXA and combination of IV and topical TXA was not significant.

Comparing with the expenses in control group, the expenses in IV and combined group decreased significantly. The reason might be the decreasing of LOS and allogenetic transfusion needs. It was reported that multiple doses of TXA could further reduce blood loss, transfusion rate and LOS, as well as oral TXA had greater cost-effectiveness in primary TKA $[17,18]$. So the expenses of patients undergoing SBTKA could be further reduced.

To our best knowledge, there have been no studies to specifically evaluate the difference between single IV TXA and combined TXA (IV and topical TXA) in the setting of SBTKA. In this study, we found that the efficacy of single IV TXA and combination of IV as well as topical (intra-articular injection) TXA was similar,

Table 3 Complications

\begin{tabular}{lllll}
\hline Complications & IV group $(n=192)$ & Combined group $(n=135)$ & Control group $(n=248)$ & 0 \\
\hline PE & 0 & 0 & 3 & - \\
DVT & 1 & 1 & 0 & -730 \\
Cardiac infarction & 0 & 0 & 0 & - \\
Acute renal failure & 0 & 0 & 1 & - \\
Superficial infection & 2 & 0 & 0 & - \\
Deep infection & 0 & 0 & 0.412 \\
\hline
\end{tabular}

PE pulmonary embolism, DVT deep venous thrombosis, CMVT calf muscular vein thrombosis 
Table 4 The baseline characteristics of patients of previous studies

\begin{tabular}{|c|c|c|c|c|c|}
\hline Location of Study & Usage & DVT & $\mathrm{PE}$ & Other adverse events & Statistical differences \\
\hline UAE (2011) & IV & Not mentioned & $1 / 20$ & Not mentioned & NS \\
\hline U.S. (2013) & IV & 0 & 0 & 0 & NS \\
\hline Turkey (2014) & IV and Topical & $1 / 41$ & 0 & 0 & NS \\
\hline U.S. (2015) & IV & $2 / 46$ & 0 & $9 / 46$ & NS \\
\hline China (2016) & IV & 0 & 0 & 0 & NS \\
\hline South Korea (2017) & Topical & Not mentioned & Not mentioned & Not mentioned & NS \\
\hline U.S. (2017) & IV & 0 & 0 & 0 & NS \\
\hline China (2019) & IV and topical & $1 / 192$ and $1 / 135$ & 0 & 2/192 and 0/135 & NS \\
\hline
\end{tabular}

DVT deep venous thrombosis, PE pulmonary embolism, UAE United Arab Emirates, IV intravenous, NS not significant

indicating combined application of TXA failed to get better results in SBTKA. However, the study of Xiong et al. showed that the combined group (IV and topical TXA) had significantly less blood loss than the IV group following primary TKA [19], which was not consistent with our study. First of all, the surgery was different, SBTKA was associated with much blood loss compared with primary TKA. In addition, the subgroup analyses in Xiong's study showed that the combined group was less total blood loss in topical TXA dose $>1.5 \mathrm{~g}$ following primary TKA. However, the dose of topical TXA was only $2 \mathrm{~g}$ in the setting of SBTKA, approximately equal to1g each TKA in our study, which was insufficient. Therefore, we just found the downtrend in combined group in blood loss but the difference between IV and combined groups was not significant after SBTKA.

As an anticoagulant, the safety of TXA had been concerned and evaluated widely. Table 4 summarized the incidence of complications from previous and this studies for patients undergoing SBTKA $[5-8,15,16,20]$. The incidence of thromboembolic events was very low and was similar between patients with or without TXA.

There are some surgery-associated factors which are associated with preoperative blood loss during TKA, especially the tourniquet and navigation. A North American database analysis showed the use of navigation in TKA could result in less perioperative transfusions [21]. In addition, our previous study indicated that the application of tourniquet could increase the transfusion risk in SBTKA [9]. However, we did not use the navigation and the tourniquet was applied for all patients in this study considering much blood loss in SBTKA. We have recognized the advantage of navigation and disadvantage of tourniquet. We will consider performing navigation TKA without tourniquet in the near future.

The study was carefully designed to reduce bias, but several limitations still existed. Firstly, the blood sample were mainly measured on POD1 as well as POD3 and the TBL was calculated based on level of Hct on POD3 in most cases. The Hct may continue to decline so the TBL that we calculated was not exact TBL. However, we believed that the potential inaccuracy due to Hct did not impact the result because of the consistency of calculation method among the three groups. Second, the perioperative management methods were not completely consistent among the different hospitals and experience of surgeons varied. In addition, the follow-up time was merely 1 month, which could be short of power to sufficiently evaluate the risk of DVT and other complications. Therefore, further studies with long-term followup are requisite.

\section{Conclusion}

The study indicates that TXA could reduce blood loss with no apparent increase in the incidence of complications during SBTKA.

\section{Abbreviations}

DVT: Deep venous thrombosis; Hb: Hemoglobin; Hct: Hematocrit; IV: Intravenous; LMWH: Low-molecular-weight heparin; LOH: Length of stay; PBV: Patient's blood volume; PE: Pulmonary embolism; POD: Postoperative day; SBTKA: Simultaneous bilateral total knee arthroplasty; TBL: Total blood loss; TKA: Total knee arthroplasty; TXA: Tranexamic acid

\section{Acknowledgements}

We would like to thank the relevant staff for guidance and assistance for their support and collaboration in our hospital. We thank Peter G. Alexander, PhD and Hang Lin, PhD, from Center for Cellular and Molecular Engineering, Department of Orthopaedic Surgery, University of Pittsburgh School of Medicine, for editing the English text of a draft of this manuscript.

\section{Authors' contributions}

ZKZ and FXP designed this study; GC, QH, ZYH and HX collected the data; GRC wrote the manuscript; $\mathrm{HL}$ and PA revised this manuscript. All authors reviewed the final manuscript. All authors agreed to be accountable for all aspects of the work.

\section{Funding}

This research was funded by the National Health and Family Planning Commission of the People's Republic of China (CN) program (201302007). The funding body had no role in the design of the study, data collection, analysis, interpretation of data and writing the manuscript.

\section{Availability of data and materials}

The datasets used and/or analyzed during the current study are available from the corresponding author on reasonable request.

\section{Ethics approval and consent to participate}

The study was a multicenter retrospective cohort study. The data was obtained from a multicenter database that was provided by 26 hospitals sponsored by 
the Chinese Health Ministry (201302007). This study was approved by the local institutional review board of West China Hospital, Sichuan University (2012268). Written informed consent (including patients' details, images or videos) was obtained from all participants.

\section{Consent for publication}

Not applicable.

\section{Competing interests}

The authors declare that they have no competing interests.

\section{Author details}

'Department of Orthopaedic surgery, West China Medical School, West China Hospital, Sichuan University, 37\# Guoxue Road, Chengdu, Sichuan Province 610041, People's Republic of China. ${ }^{2}$ Department of Orthopedics, The Eighth Affiliated Hospital, Sun Yat-sen University, Shenzhen, Guangdong Province, People's Republic of China. ${ }^{3}$ Center for Cellular and Molecular Engineering, Department of Orthopaedic Surgery, University of Pittsburgh School of Medicine, Pittsburgh, USA.

Received: 8 April 2019 Accepted: 25 June 2019

Published online: 12 July 2019

\section{References}

1. Blajchman MA, Beckers EA, Dickmeiss E, Lin L, Moore G, Muylle L. Bacterial detection of platelets: current problems and possible resolutions. Transfus Med Rev. 2005;19(4):259-72.

2. Fuller AK, Uglik KM, Savage WJ, Ness PM, King KE. Bacterial culture reduces but does not eliminate the risk of septic transfusion reactions to singledonor platelets. Transfusion. 2009:49(12):2588-93.

3. Hogan CA, Golightly LK, Phong S, Dayton MR, Lyda C, Barber GR. Perioperative blood loss in total hip and knee arthroplasty: outcomes associated with intravenous tranexamic acid use in an academic medical center. SAGE Open Med. 2016:4:2050312116637024.

4. Sassoon A, Nam D, Jackups R, Johnson SR, Nunley RM, Barrack RL. Tranexamic acid: optimal blood loss management in surface replacement arthroplasty. Bone Joint J. 2016;98-b(2):173-8.

5. Bagsby DT, Samujh CA, Vissing JL, Empson JA, Pomeroy DL, Malkani AL. Tranexamic acid decreases incidence of blood transfusion in simultaneous bilateral Total knee arthroplasty. J Arthroplast. 2015;30(12):2106-9.

6. Chen X, Cao X, Yang C, Guo K, Zhu Q, Zhu J. Effectiveness and safety of fixed-dose tranexamic acid in simultaneous bilateral Total knee arthroplasty: a randomized double-blind controlled trial. J Arthroplast. 2016;31(11):2471-5.

7. Prieto HA, Vincent HK, Deen JT, lams DA, Parvataneni HK. Tranexamic acid effectively reduces blood loss and transfusion rates during simultaneous bilateral Total knee arthroplasty. J Knee Surg. 2018:31(3):270-6.

8. Suh DW, Han SB, Park JH, Cheong K, Kyung BS. Intravenous iron supplementation with intra-articular administration of tranexamic acid reduces the rate of allogeneic transfusions after simultaneous bilateral total knee arthroplasty. Blood Transfus. 2017;15(6):506-11.

9. Cao G, Huang Z, Huang Q, Zhang S, Xu B, Pei F. Incidence and risk factors for blood transfusion in simultaneous bilateral Total joint arthroplasty: a multicenter retrospective study. J Arthroplast. 2018;33(7):2087-91.

10. Gross JB. Estimating allowable blood loss: corrected for dilution Anesthesiology. 1983;58(3):277-80.

11. Nadler SB, Hidalgo JH, Bloch T. Prediction of blood volume in normal human adults. Surgery. 1962;51(2):224-32.

12. Liu X, Zhang X, Chen Y, Wang Q, Jiang Y, Zeng B. Hidden blood loss after total hip arthroplasty. J Arthroplast. 2011;26(7):1100-1105.e1101.

13. Bedard NA, Pugely AJ, Lux NR, Liu SS, Gao Y, Callaghan JJ. Recent trends in blood utilization after primary hip and knee arthroplasty. J Arthroplast. 2017; 32(3):724-7.

14. Parvizi J, Chaudhry S, Rasouli MR, Pulido L, Joshi A, Herman JH, Rothman RH. Who needs autologous blood donation in joint replacement? J Knee Surg. 2011;24(1):25-31.

15. Karaaslan F, Karaoglu S, Mermerkaya MU, Baktir A. Reducing blood loss in simultaneous bilateral total knee arthroplasty: combined intravenous-intraarticular tranexamic acid administration. A prospective randomized controlled trial. Knee. 2015;22(2):131-5.
16. Karam JA, Bloomfield MR, Dilorio TM, Irizarry AM, Sharkey PF. Evaluation of the efficacy and safety of tranexamic acid for reducing blood loss in bilateral total knee arthroplasty. J Arthroplast. 2014;29(3):501-3.

17. Cao G, Xie J, Huang Z, Huang Q, Chen G, Lei Y, Xu H, Pei F. Efficacy and safety of multiple boluses of oral versus intravenous tranexamic acid at reducing blood loss after primary total knee arthroplasty without a tourniquet: a prospective randomized clinical trial. Thromb Res. 2018;171:68-73.

18. Lei $Y, X i e J, X u$ B, Xie X, Huang Q, Pei F. The efficacy and safety of multipledose intravenous tranexamic acid on blood loss following total knee arthroplasty: a randomized controlled trial. Int Orthop. 2017;41(10):2053-9.

19. Xiong H, Liu Y, Zeng Y, Wu Y, Shen B. The efficacy and safety of combined administration of intravenous and topical tranexamic acid in primary total knee arthroplasty: a meta-analysis of randomized controlled trials. BMC Musculoskelet Disord. 2018;19(1):321.

20. MacGillivray RG, Tarabichi SB, Hawari MF, Raoof NT. Tranexamic acid to reduce blood loss after bilateral total knee arthroplasty: a prospective, randomized double blind study. J Arthroplast. 2011;26(1):24-8.

21. Liodakis E, Antoniou J, Zukor DJ, Huk OL, Epure LM, Bergeron SG. Navigated vs conventional Total knee arthroplasty: is there a difference in the rate of respiratory complications and transfusions? J Arthroplast. 2016;31(10):2273-7.

\section{Publisher's Note}

Springer Nature remains neutral with regard to jurisdictional claims in published maps and institutional affiliations.

\section{Ready to submit your research? Choose BMC and benefit from:}

- fast, convenient online submission

- thorough peer review by experienced researchers in your field

- rapid publication on acceptance

- support for research data, including large and complex data types

- gold Open Access which fosters wider collaboration and increased citations

- maximum visibility for your research: over $100 \mathrm{M}$ website views per year

At BMC, research is always in progress.

Learn more biomedcentral.com/submissions 